\title{
Long-term seasonal nutrient limiting patterns at Meiliang Bay in a large, shallow and subtropical Lake Taihu, China
}

\author{
Rui YE, ${ }^{1}$ Kun SHAN,${ }^{2,3}$ Hailong GAO,${ }^{1}$ Ruibin ZHANG, ${ }^{1}$ Shuai WANG, ${ }^{4}$ Xin QIAN ${ }^{1 *}$ \\ ${ }^{1}$ State Key Laboratory of Pollution Control and Resource Reuse, School of the Environment, Nanjing University, Nanjing 210023; \\ ${ }^{2}$ State Key Laboratory of Freshwater Ecology and Biotechnology, Institute of Hydrobiology, Chinese Academy of Sciences, Wuhan \\ 430072; ${ }^{3}$ University of Chinese Academy of Sciences, Beijing 100049; ${ }^{4}$ Environmental Protection Department of Anhui Province, \\ Hefei 230071, China \\ *Corresponding author: xqian@nju.edu.cn
}

\begin{abstract}
Lake Taihu has undergone severe eutrophication in the past three decades, and harmful cyanobacteria blooms occur nearly every year in Meiliang Bay at the north end of the lake. To elucidate the potential relationship between seasonal nutrient limitation and phytoplankton proliferation, a 20-year (1992-2011) time series of nutrient limitation in Meiliang Bay was analysed for deviations between trophic state index (TSI) parameters. Results showed that patterns of nutrient limitation in Meiliang Bay were distinctly seasonal, where phytoplankton growth was generally phosphorus (P)-limited in winter and spring, but nitrogen (N)-limited mainly occurred in summer and fall. This general pattern, however, shifted into N limitation across the four seasons during the mid-1990s because a rapid increase in industrialization led to a significant rise in the input of $N$ and $P$ from inflowing tributaries. The initial patterns were restored by environmental regulation in the end of 1990s, including the Zero Actions plan. Using routine monitoring data, a generalised additive model (GAM) with time and deviations between trophic state indexes for nitrogen and phosphorus (TSIN-TSIP) as explanatory variables was used to explore which nutrient was responsible for limitation of phytoplankton chlorophyll-a (Chl-a) in different seasons. Surprisingly, the model revealed a weak N limitation (TSIN-TSIP=-10) corresponded to peak values of Chl-a in summer-autumn season, which is probably because the phytoplankton community is co-limited by $N$ and $P$ during the period. The shift of nutrition limitation during winter-spring would partially explain high values of Chl-a throughout 1996. This study suggests that seasonal patterns of nutrient limitation must be considered to develop effective management measures to control cyanobacterial blooms.
\end{abstract}

Key words: Eutrophication, trophic state index, nutrient limitation, generalized additive model, Meiliang Bay.

Received: November 2014. Accepted: March 2015.

\section{INTRODUCTION}

Eutrophication is the most widespread ecological problem in freshwater and marine ecosystems worldwide (Paerl, 1988; Huisman, 2005; Conley et al., 2009). In many shallow lakes in the past four decades, nitrogen $(\mathrm{N})$ and phosphorus $(\mathrm{P})$ enrichment from untreated sewage effluent and agricultural run-off containing fertilizers has caused harmful algal blooms, fish kills, reduction of biodiversity, and a series of related problems (Carmichael, 1992; Dokulil and Teubner, 2000; Paerl and Huisman, 2008).

Lake Taihu, the third largest shallow lake in China, with an area of $2338 \mathrm{~km}^{2}$ and an average depth of only $1.9 \mathrm{~m}$ (Qin et al., 2004), is one of the primary sources of drinking water. In recent three decades, increased nutrient inputs related to rapid growth of population and economy, and lakewide nutrient cycling characters have led to severe eutrophication in certain lake areas (Qin et al., 2007; Paerl et al., 2011) and the decrease of aquatic plants of the lake (Zhu, 2008). In particular, Meiliang Bay has experienced frequent cyanobacterial blooms, which seriously impair water quality in adjacent areas used as sources of drinking water (Song et al., 2007; Liu et al., 2011). Large quantities of nutrients $(\mathrm{N}$ and $\mathrm{P})$ in riverine discharge in Meiliang Bay have promoted phytoplankton growth (Chen et al., 2003a). In most earlier research work of nutrient limitation to phytoplankton, Meiliang Bay has long been assumed to be Plimited based on year-scale data, as supported by analyses of total nitrogen:total phosphorus (TN:TP; Vant et al., 1998). Chen et al. (2003a) used the Redfield Ratio (Redfield, 1958) to conclude that $\mathrm{N}$ was not the limiting nutrient during a 9-year study period in Meiliang Bay. Dokulil et al. (2000) found that $\mathrm{P}$ and light were the key limiting factors based on year-scale data in Lake Taihu (Meiliang Bay). Recently some studies suggested that, controlled nutrient bioassay experiments during 2008, 2009 and 2011 found nutrient limiting state alternated seasonally between $\mathrm{N}$ and P in Meiliang Bay (Xu et al., 2010, 2013; Paerl et al., 2011; Yue et al., 2014), with P-limited phytoplankton growth in winter and spring, and $\mathrm{N}$ was the primary limiting nutrient as well as P being a secondarily limiting nutrient in summer and fall. Furthermore, without considering inter-annual variability, these nutrient bioassays experiments found that 
seasonal patterns of nutrient limitation also significantly impacted algal dynamics in the study period. However, there has not been an historical time series nutrient bioassays in Meiliang Bay, which is very important to understand if the seasonal variation in nutrient limitation in Meiliang Bay forms consistent patterns over extended periods of time.

The present study explored seasonal patterns of nutrient limitation using long-term data series of nutrients and phytoplankton chlorophyll-a in Meiliang Bay taken during monthly monitoring from 1992 to 2011. Deviations among trophic state indices (Carlson, 1977) were used to determine nutrient ( $\mathrm{N}$ and $\mathrm{P}$ ) limitation. The following questions were addressed: i) was there a consistent seasonal shift in nutrient limitation in Meiliang Bay in the past twenty years? ii) were external sources (riverine inflow) or internal sources (sediment) the most likely contributor to shifts in nutrient limitation in the area? iii) what was the nature of the response of phytoplankton chlorophyll-a to seasonal shifts in nutrient limitation?

\section{METHODS}

\section{Study area}

Lake Taihu is located in the Yangtze River Delta in

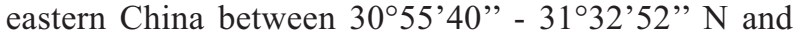
11952'32" - 120³6’10" E (Qin et al., 2004). The lake basin is located within the temperate and subtropical zone and has a moist and semi-moist monsoon climate with a clear distinction between seasons. Spring, summer, autumn and winter in the Lake Taihu basin occur from March-May, June-August, September-November, and December-February, respectively.

Meiliang Bay is one of the most eutrophic bays in the northern part of the Lake Taihu (Fig. 1), with surface area of $100 \mathrm{~km}^{2}$ and a depth of 1.8-2.3 m. There are two main

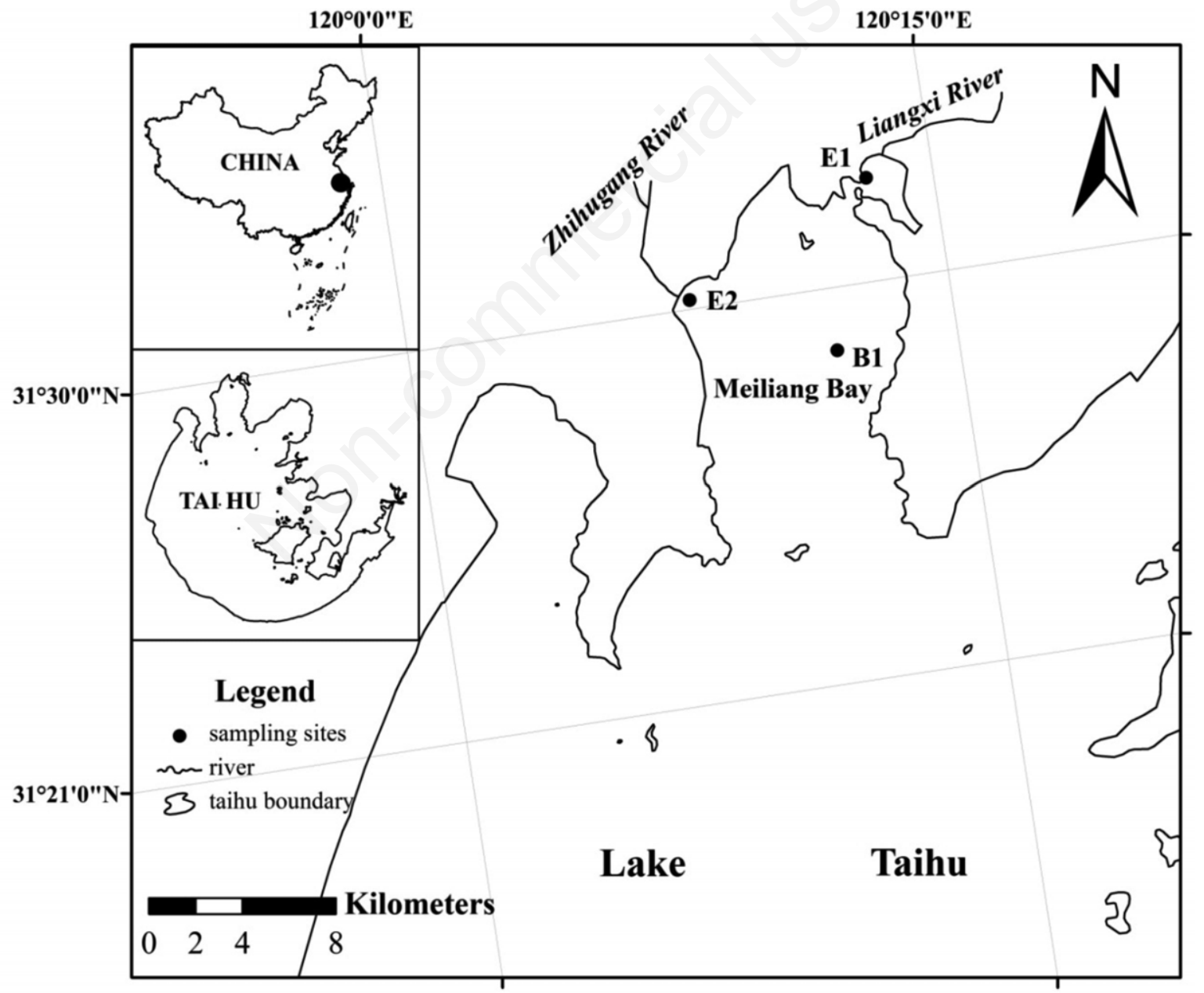

Fig. 1. Location of Lake Taihu in China and sampling sites in Meiliang Bay. Phytoplankton chlorophyll-a (Chl-a) together with environmental variables were monitored monthly at sites E1, E2 and B1, generally in the middle of each month. Stations E1 and E2 were located near the mouth of Liangxi River and Zhihugang River, respectively. 
inflowing rivers, the Zhihugang and the Liangxi, connected to the Meiliang Bay (Fig. 1). According to Zhu (1994), the catchment of the Zhihugang River contains substantial countryside industry. The catchment of the Liangxi River is less industrial, but the river passes through the city of Wuxi, which has a population over six million. Untreated wastewater from residential areas and factories are discharged into both rivers. Heavy industrial and agricultural pollution as well as domestic sewage have caused frequent blooms of Microcystis spp. in Meiliang Bay in the past decades (Dokulil et al., 2000; Chen et al., 2003b).

To investigate long-term fluctuations in nutrient limitation, three stations distributed in Meiliang Bay were selected (Fig. 1). Station E1 (31'32'22.85" N, 120 13'9.98" E) was near the Liangxi River, and Station E2 $\left(31^{\circ} 30^{\prime} 13.79^{\prime \prime} \mathrm{N}, 120^{\circ} 7^{\prime} 52.21^{\prime \prime} \mathrm{E}\right)$ was near the Zhihugang River. Samples at these two stations were used to estimate nutrient inputs from the catchment area of Meiliang Bay. Station B1 (31'28’34.79” N, 120¹1'39.59”E) was located in open water, and samples taken there monitored the overall nutrient state in the bay.

\section{Data collection and measurement methods}

Data from 1992 to 2011 were available for three sites (E1, E2 and B1) in Meiliang Bay (Fig. 1). The data from 1992 to 2008 were obtained from the Taihu Laboratory for Lake Ecosystem Research (TLLER), Nanjing Institute of Geography and Limnology, Chinese Academy of Science. In addition, a 3-year observation was directly conducted from field investigation at Site B1 from 2009 through 2011 in this study.

Monthly sampling was conducted from October 1991 to December 2008. Integrated water samples were taken using plastic tubes ( $2 \mathrm{~m}$ long by $10 \mathrm{~cm}$ diameter). Physical and chemical parameters such as total nitrogen (TN) and total phosphorus (TP) concentrations were analysed according to the Chinese standard methods for the lake eutrophication survey (Jin and Tu, 1990). Phytoplankton chlorophyll-a (Chl-a) concentrations were calculated from spectrophotometric measurements after extraction in $90 \%$ hot ethanol (Lorenzen, 1967). Measurement methods and analyses for data collected from 2009 to 2011 were identical to that of TLLER.

\section{Inference of nutrient limitation}

In the present study, values of the trophic state index (TSI) (Carlson, 1977; Kratzer and Brezonik, 1981) were calculated from measured total $\mathrm{P}$ and $\mathrm{N}$ concentrations, and deviations between both values of indexes were used to determine nutrient limitation status. The method of TSI indexes deviation integrated the multiple factors and had a good stability for studying the historical variation of nutrient limitation (Havens, 1995).
$\mathrm{TSIP}=10 \times(6-\ln (48 / \mathrm{TP}) / \ln 2)$

$\mathrm{TSIN}=10 \times(6-(\ln 1.47 / \mathrm{TN}) / \ln 2)$

Kratzer and Brezonik (1981) developed an N index (TSIN, eq. 2) based on chlorophyll-N regression relationships for forty N-limited Florida lakes. To understand $\mathrm{N}$ and P limitation, Kratzer and Brezonik also performed standard nutrient bioassays in the forty lakes. They proved that instances of TSIN-TSIP $<0$ corresponded accurately with bioassay results of nitrogen $(\mathrm{N})$ limitation, while instances of TSIN-TSIP $>0$ corresponded with phosphorus (P) limitation.

\section{Validation of nutrients limitation by the trophic state index method}

TSIs in Meiliang Bay were calculated using the methods described by Carlson (1977) and Kratzer and Brezonik (1981) as a means to evaluate patterns of nutrient limitation, which was previously widely applied in Lake Okeechobee by the well validation of comparing TSIs with standard nutrient bioassay experiments (Aldridge et al., 1995; Havens, 1995). Thus, prior to application to the long-term dataset, this approach needs to be validated for Meiliang Bay using bioassay experiments results from Paerl et al. (2011) and Xu et al. (2010).

Monthly TN and TP between 2008 and 2009 were calculated from bioassay results (Paerl et al., 2011; Xu et al., 2010) (Fig. 2). Values of TSIN $>$ TSIP during winter and spring indicated P limitation of phytoplankton growth, while summer and fall measurements of TSIN $<$ TSIP suggested $\mathrm{N}$ was the primary limiting nutrient. The agreement

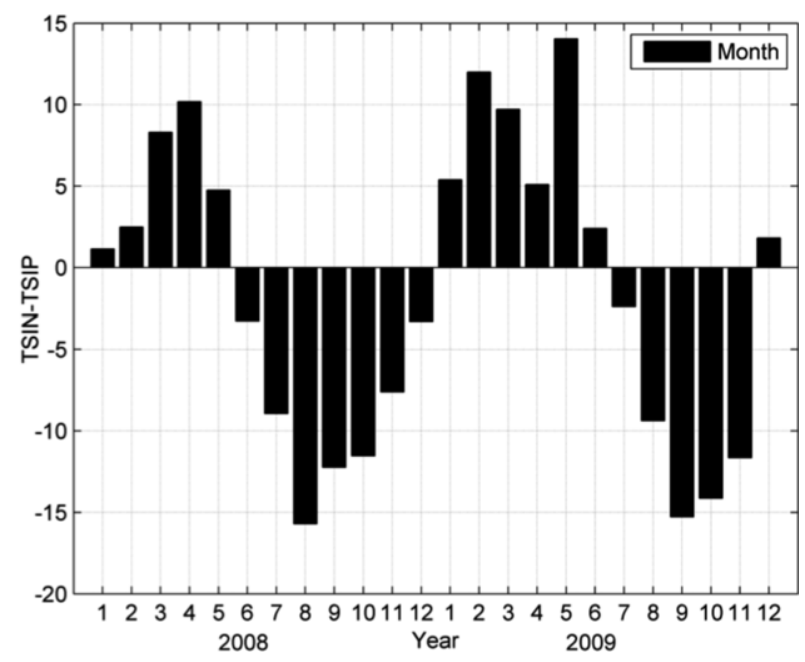

Fig. 2. Validated seasonal nutrients limitation by the trophic state index (TSI) method in 2008 and 2009. 
between results of the two approaches (TSI values and bioassays) not only validated the reliability of using TSI to assess nutrient limitation status, but also provided further evidence of the seasonal change in nutrient limitation in Meiliang Bay (Fig. 2). Consequently, TSI deviations were applied to reconstruct historical patterns of nutrient limitation in Meiliang Bay in Lake Taihu.

\section{Assessing the effects of seasonal nutrient limitation on phytoplankton growth}

The seasonal patterns of water quality parameters (TN, TP, Chl-a) were examined visually using boxplots showing the median, $25^{\text {th }}$ and $75^{\text {th }}$ percentiles over the 20 years of data collection (Mcgill et al., 1978). Independent $t$-tests were conducted at the 0.05 confidence level to test the variance between group sample values.

Responses of phytoplankton over the time series and the deviation value between trophic state indexes for $\mathrm{N}$ and P (TSIN-TSIP) were modelled using a generalized additive model (GAM) (Wood, 2006). The superiority of the GAM is its adaptability for non-normally distributed variables. In ecological studies, because the assumption of normality is nearly always violated for some variables, and there are often non-linear relationships between species and environmental factors, GAM is a useful and oft-applied tool for ecological researchers (Salmaso et al., 2012; Tao et al., 2012). In this study, GAM was used to assess the effects of seasonal nutrient limitation on phytoplankton growth. To test the interaction between seasonal effects and the deviation value of TSI, we created a categorical variable season, which had two values: one for winter-spring and zero for summer-autumn:

$\mathrm{Chl}-\mathrm{a}=\beta_{0}+s($ Time $)+s($ TSIN - TSIP, by $=$ season $)+\varepsilon$ (eq. 3) where $s$ is the smoothing function based on a cubic regression spline. A graph is required to visualize the function $s$. In contrast to regression models, GAM provides a smoother rather than an equation, which can be evaluated by plotting (Zuur et al., 2009). Statistical analyses were carried out using $\mathrm{R}$ version 3.0.3. The $m g c v$ package (Wood, 2011) was used for GAM model-fitting because it can perform cross-validation, which makes it robust against outliers and data that is non-normally distributed.

\section{RESULTS}

\section{Long-term trends of eutrophication in Meiliang Bay}

Monthly averages of TN, TP and Chl-a in Meiliang Bay from 1992 to 2011 are shown in Fig. 3. TN concentrations ranged from 0.61-9.63 $\mathrm{mg} \mathrm{L}^{-1}$ in Meiliang Bay
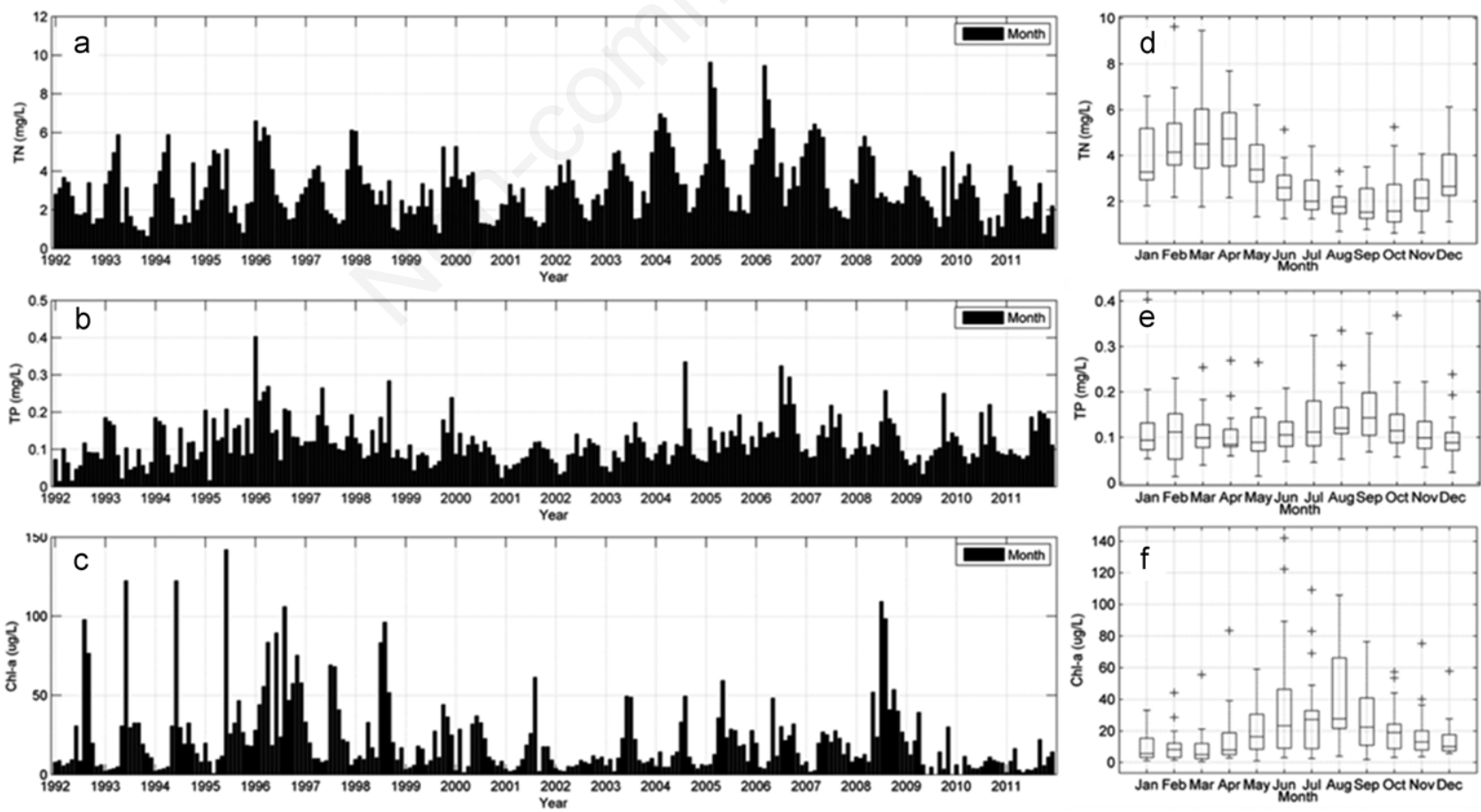

Fig. 3. Long-term (1992-2011) trends in concentrations of total nitrogen (TN), total phosphorus (TP) and chlorophyll-a (Chl-a) at Meiliang Bay in Lake Taihu: a) TN. b) TP. c) Chl-a. Monthly boxplot of TN, TP and Chl-a from 20 years data in Meiliang Bay: d) TN. e) TP. f) Chl-a. The crosses "+" represent outliers. 
(Fig. 3a), with an average of $3.17 \mathrm{mg} \mathrm{L}^{-1}$ during the 20 years of study. Maximal values normally appeared in winter and spring, whereas minimal values were usually confined to summer and autumn (Fig. 3d). Similar to TN, concentrations of TP ranged two orders of magnitude from $0.014-0.40 \mathrm{mg} \mathrm{L}^{-1}$ (Fig. 3b), with a 20 -year average of $0.20 \mathrm{mg} \mathrm{L}^{-1}$. However, TP revealed an inverse seasonal pattern to TN, with maxima from June to September and minima occurring from winter to early spring (Fig. 3e). Fluctuations in Chl-a followed changes in TP. Concentrations ranged from $0.55-142.00 \mu \mathrm{g} \mathrm{L}^{-1}$ (Fig. 3c), and summer or autumn maxima (Fig. 3f) indicated recurring seasonal phytoplankton blooms.

Episodic data collected over long periods in Meiliang Bay can provide valuable understanding of the evolution of eutrophication. In general, TN, TP, and Chl-a all increased between 1992 and 1996: average annual TN increased from 2.40 to $3.65 \mathrm{mg} \mathrm{L}^{-1}$, TP rose from 0.07 to $0.19 \mathrm{mg} \mathrm{L}^{-1}$, and Chl-a concentrations went from 23.48 to $57.13 \mu \mathrm{g} \mathrm{L}^{-1}$. Moreover, annual peak values of TN and TP ranged from 3.67-6.60 $\mathrm{mg} \mathrm{L}^{-1}$ and from $0.12-0.40 \mathrm{mg} \mathrm{L}^{-1}$, respectively (Fig. 3a, 3b). The annual peak of Chl-a changed from 97.73 $\mu \mathrm{g} \mathrm{L}^{-1}$ prior to 1995 to $142.00 \mu \mathrm{g} \mathrm{L}^{-1}$ in 1995 (Fig. 3c), which was the highest average Chl-a concentration during the study period. Prior to 1995 , algal blooms only occurred in an individual month in each summer and autumn (Fig. 3c). However, between 1995 and 1996, algal bloom duration extended across all summer and autumn months. In fact, the average annual concentration of Chl-a was 57.13 $\mu \mathrm{g} \mathrm{L}^{-1}$ in 1996 (Fig. 3c), the most serious algal bloom during the 20-year period. All three parameters decreased from 1997 to 2000, at which point annual values neared those of 1992 (TN $2.58 \mathrm{mg} \mathrm{L}^{-1}$, TP $0.10 \mathrm{mg} \mathrm{L}^{-1}$ and Chl-a $16.22 \mu \mathrm{g}$ $\mathrm{L}^{-1}$; Fig. 3a,b,c). The decline in nutrient concentrations after 1996 may be explained in part by reductions in external nutrient inputs from the catchment imposed by the local government in 1995 (Chen et al., 2003a).

In the beginning of $21^{\text {st }}$ century, TN and TP increased gradually, reaching its highest level from 2001 to 2006. Average annual concentrations of TN increased from 2.26 to $4.97 \mathrm{mg} \mathrm{L}^{-1}$, and TP increased from 0.08 to $0.18 \mathrm{mg} \mathrm{L}^{-1}$. Concentrations of $\mathrm{TN}$ subsequently declined, returning to $2.24 \mathrm{mg} \mathrm{L}^{-1}$ while there was no obvious change in TP. Between 2001 and 2004, concentrations and seasonal variation in Chl-a were fairly low and stable, although average annual values increased from 6.62 to $17.04 \mu \mathrm{g} \mathrm{L}{ }^{-1}$ with peak values rising from 11.81 to $61.25 \mu \mathrm{g} \mathrm{L} \mathrm{L}^{-1}$ (Fig. 3c). Since 2005, however, there has been an increasing trend in Chl-a, with very highs in 2008 , at $40.49 \mu \mathrm{g} \mathrm{L}^{-1}$ on average and a peak value of $109.28 \mu \mathrm{g} \mathrm{L}^{-1}$ (Fig. 3c). Cyanobacteria blooms in Lake Taihu caused a water crisis in 2007 (Guo, 2007; Yang et al., 2008; Qin et al., 2010; Zhang et al., 2010; Qin et al., 2013), which was closely related to continuous enrichment of nutrients (both $\mathrm{N}$ and
P). From 2009 to 2011, Chl-a gradually dropped (annual average of $7.68 \mu \mathrm{g} \mathrm{L}^{-1}$ ), which may have been caused by the reduction of external pollution and related recovery measures in the lake.

\section{Historical fluctuations in nutrient limitation}

Historical patterns of seasonal nutrient limitation (Fig. 4) inferred from TSI deviation corroborated findings of a series of nutrient bioassay experiments between 2008 and 2011 in Meiliang Bay (Xu et al., 2013; Yue et al., 2014). Analysis of 20 years of deviation in TSI values (Fig. 4) showed a distinct seasonal pattern of nutrient limitation with roughly three stages: i) during 1992-1995, seasonal shifts from $P$ limitation of phytoplankton growth in winter and spring to $\mathrm{N}$ limitation in summer and fall occurred; ii) during 1995-2000, there was a loss of seasonal patterns, where $\mathrm{N}$ limitation dominated throughout the year. This pattern was most obvious during 1996-1997 and gradually weakened during 1998-2000, when slight P limitation emerged in some winter and spring months; iii) after 2000, patterns of seasonal nutrient limitation began to return to those observed prior to 1995, and P limitation gradually strengthened in winter and spring. Maximum P limitation occurred from the winter of 2001 to the spring of 2002, after which slow weakening occurred. N limitation of summer and fall kept a relatively stable state and gradually strengthened until 2010 and 2011.

\section{Interannual and seasonal changes of influent nitrogen and phosphorus at Meiliang Bay}

Both concentrations of TN and TP showed strong seasonal variation in the Zhihugang and Liangxi Rivers, which were the two main inflowing rivers in the Meiliang Bay sub-basin. Maximum TN values occurred in winter and spring, whereas minimum values were observed in summer and autumn during the 20-yr (1992-2011) period (Fig. 5 a,c). Similarly, as to the changes of TP concentration in the both rivers, higher levels appeared in spring, while lower in summer (Fig. 5 b,d).

From the interannual point of view, there were significant fluctuations of nutrients concentrations between 1992-2000 in the Zhihugang and Liangxi Rivers. Data analysis of TN and TP from 1992 to 1995 indicated that the average annual TN in the Liangxi River increased from 6.67 to $6.94 \mathrm{mg} \mathrm{L}^{-1}$ (Fig. 6a), while TP increased from 0.20 to $0.31 \mathrm{mg} \mathrm{L}^{-1}$ (Fig. 6b); in the Zhihugang River, average annual TN increased from 1.68 to $5.62 \mathrm{mg}$ $\mathrm{L}^{-1}$ (Fig. 6c), and TP increased from 0.05 to $0.33 \mathrm{mg} \mathrm{L}^{-1}$ (Fig. 6d). As to the two rivers, maximum average annual TN and TP concentration almost occurred in 1996, subsequently, the concentration of TN and TP declined rapidly, especially the significant dropped magnitude of TP, which might be related to nutrients management actions. 


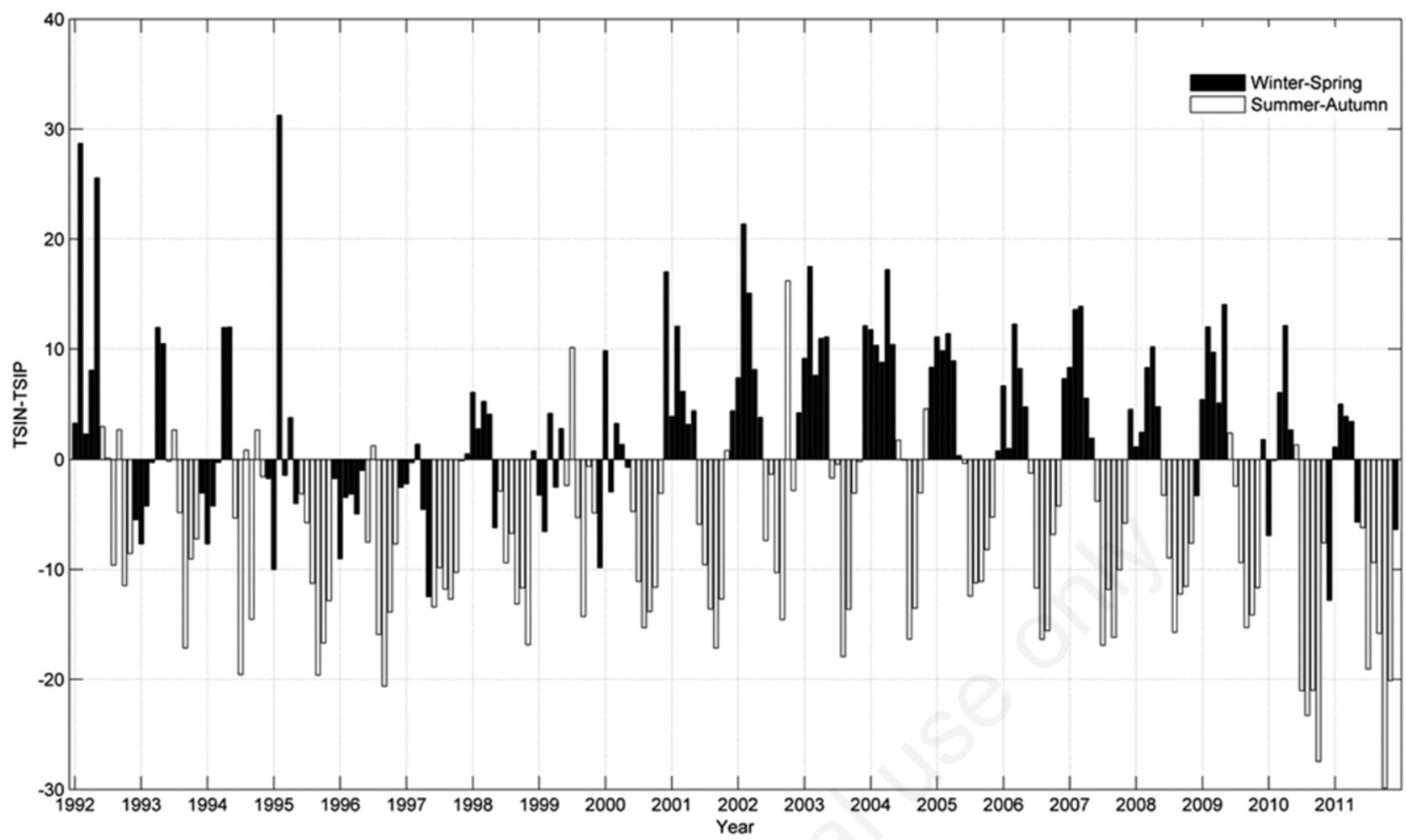

Fig. 4. Historical deviations of TSIN and TSIP (TSIN-TSIP) in the Meiliang Bay. Vertical bars represent monthly data. Deviations above the zero isocline indicate P limitation (TSIN-TSIP $>0$ ), while deviations below the isocline represent N limitation (TSIN-TSIP $<0$ ).
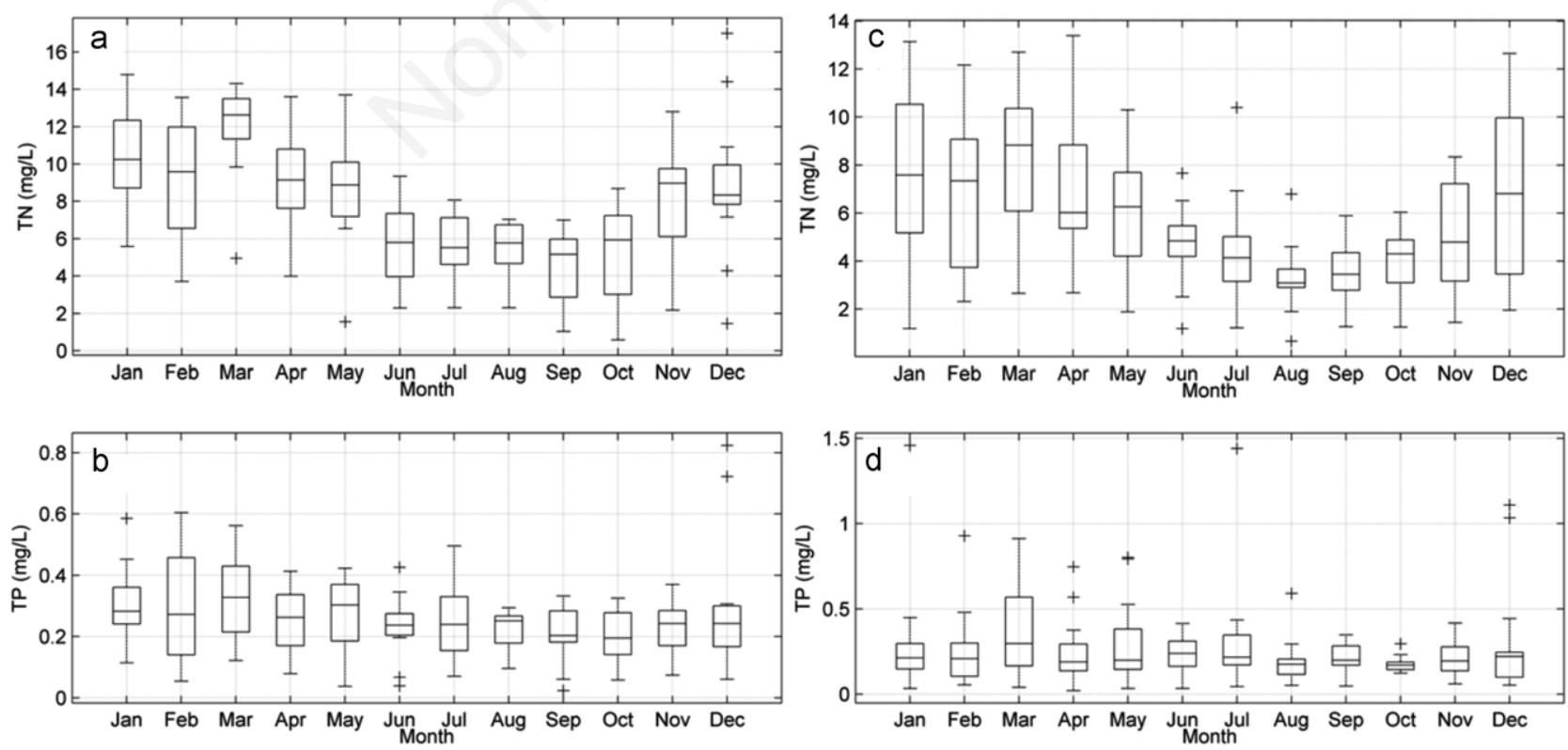

Fig. 5. Boxplot of TN and TP by month in Liangxi River (a, b) and Zhihugang River (c, d) based on 20 years' data. 


\section{DISCUSSION}

The formation of seasonal patterns of nutrient limitation

Analysis of deviation in TSI calculated from the twenty years of monitoring data demonstrated a seasonal shift in $\mathrm{N}$ and $\mathrm{P}$ limitation in Meiliang Bay. Further analyses indicated that limitation patterns were closely related to variation in climate and nutrient sources in the Meiliang Bay area.

Meiliang Bay has a subtropical monsoon climate, with four distinct seasons. In the Lake Taihu basin, summer and fall air temperatures are significantly higher than winter and spring. The majority of precipitation occurs in summer through the lengthy meiyu (plum rain) and typhoon periods. Rainfall in winter and spring accounts for a small proportion of overall precipitation. In the Meiliang Bay sub-basin, the Zhihugang and Liangxi Rivers transport non-point source and point source nutrients into the bay from upstream agriculture and municipal sewage, respectively, which propagates the aligned seasonal patterns in weather and nutrient loading in the bay. Across nearly 20 years of seasonal changes in nutrients in the Zhihugang and Liangxi Rivers, higher concentrations of TN occurred in winter and spring $(t$-test, $\mathrm{P}<0.05)$ (Fig. 5), following seasonal patterns of TN in Meiliang Bay. This suggests that $\mathrm{N}$ concentrations in Meiliang Bay may be driven by loading from the inflowing rivers. In contrast, high concentrations of TP in both rivers were generally found in spring, though levels of TP in Meiliang Bay were normally high in summer-fall and low in winter-spring. This contradiction between the timing of patterns of TP in Meiliang Bay and its tributaries suggests that the high summer P concentration in Meiliang Bay may be caused by within-lake processes such as benthic release.

Previous work in Lake Taihu showed that $\mathrm{N}$ loading came primarily from agricultural non-point pollution sources, while $\mathrm{P}$ inputs were mainly from domestic sewage (Qin et al., 2007). Moreover, studies have demonstrated a strong correlation between nutrient loading from agricultural non-point sources and rainfall in winter and spring (Chen et al., 2010; Qiao et al., 2012). Thus, during periods of agricultural fertilizer application to cultivated land in the Lake Taihu basin in the winter and spring, $\mathrm{N}$ source of high concentration were carried by rainwater into the rivers. These $\mathrm{N}$ inputs, in addition to low rates of biogeochemical cycling in the inner bay, led to the formation of $\mathrm{P}$ limitation in the winter and spring.

Analysis of deviations in TSI showed that algae in Meiliang Bay were generally N-limited in the summer and fall. $\mathrm{N}$ limitation is caused by insufficient $\mathrm{N}$ source in the high algal growth season, where fast initial growth of cyanobacteria bloom leads to rapid $\mathrm{N}$ uptake in the water column by algae. Upon death, the algae settle to the benthos and cause $\mathrm{N}$ loss through denitrification in the sediment bed, which, in return, amplifies N-limiting conditions (Chen et al., 2012). Although studies of other shallow lakes have found that $\mathrm{N}$-fixing cyanobacteria may supplement $\mathrm{N}$
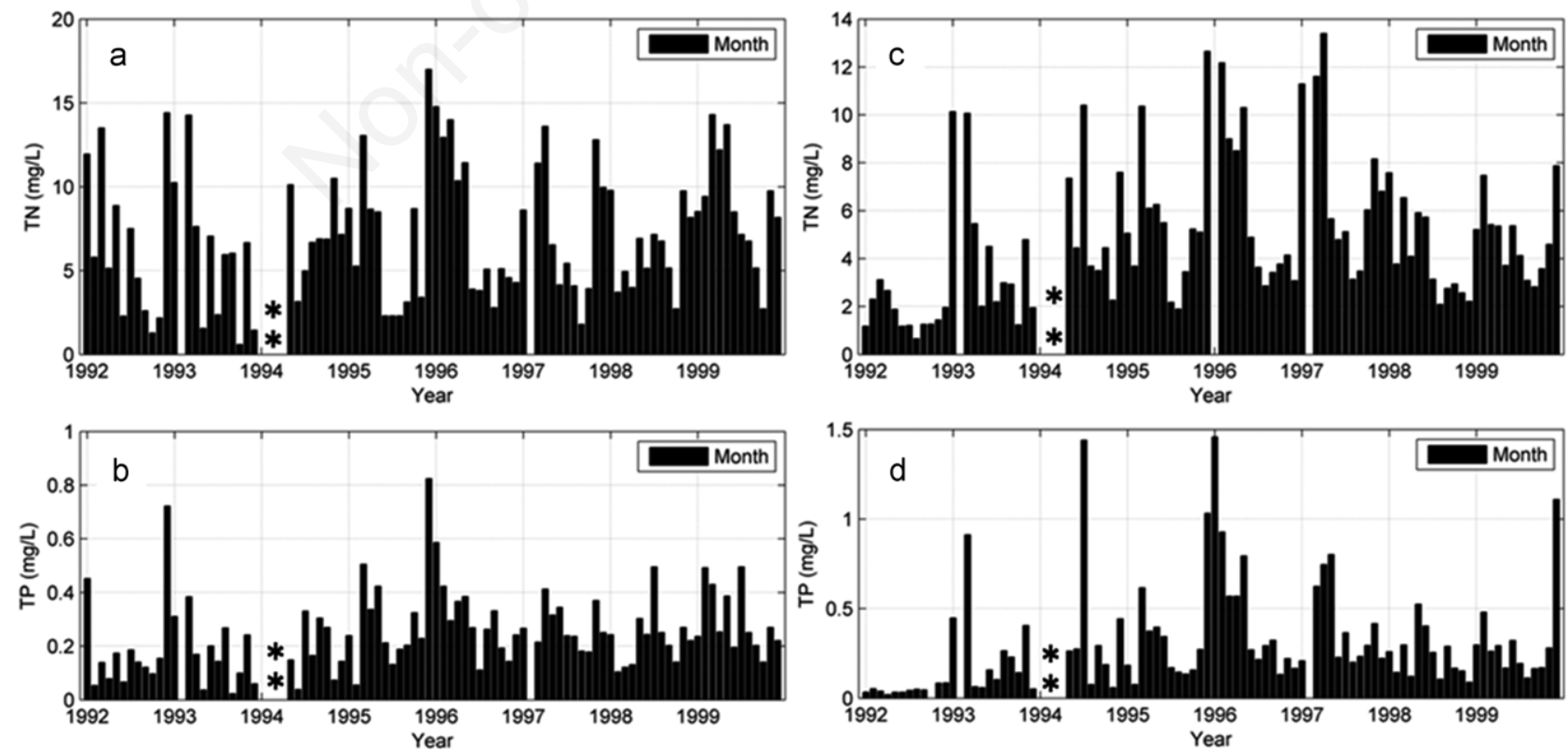

Fig. 6. Fluctuations in TN and TP in the LiangXi River (a, b) and Zhihugang River (c, d) from 1992 to 1999. The asterisk represents missing samples - dates on which sampling did not occur. 
content in the water column (Mccarthy et al., 2009), during periods of cyanobacterial blooms, past research showed that the proportion of $\mathrm{N}$-fixing cyanobacteria and $\mathrm{N}$ fixation efficiency were low in Lake Taihu (Mccarthy et al., 2007; Paerl et al., 2011). Hence, $\mathrm{N}$ concentrations in Meiliang Bay may have had little supplementation in summer and fall (Fig. 3a). In contrast, though cyanobacterial growth absorbed a large mass of $\mathrm{P}$ during the bloom period, there was complementary P release from the sediment caused by the low-oxygen, elevated $\mathrm{pH}$, and high-temperature conditions that occurred with the high rates of cyanobacterial growth and death on the sediment surface (Søndergaard et al., 2003; Xie et al., 2003; Conley, 2012). All these processes can influence seasonal fluctuation in $\mathrm{N}$ concentrations and $\mathrm{N}$ limitation of phytoplankton in Meiliang Bay during summer and fall.

Overall, climatic variation across seasons in the Lake Taihu basin and the resulting variation in external $\mathrm{N}$ and $P$ inputs from the tributaries of Meiliang Bay as well as internal $\mathrm{P}$ release from the sediment caused winter and springtime $\mathrm{P}$ limitation and summer and autumnal $\mathrm{N}$ limitation in Meiliang Bay.

\section{Collapse and recovery of patterns of nutrient limitation}

Seasonal patterns of nutrient limitation shifted significantly in 1990s (Fig. 4). Deviations in TSI in the early 1990s showed that $P$ limitation of phytoplankton growth occurred in spring and winter in Meiliang Bay, while $\mathrm{N}$ was the primary limiting nutrient in summer and fall. In the mid-1990s, however, there was a significant shift in the deviation in TSIN-TSIP (Fig. 4), indicating a transition from $\mathrm{P}$ limitation in winter-spring and $\mathrm{N}$ limitation in summer-autumn prior to 1995 to $\mathrm{N}$ limitation across all four seasons from 1995-1997. Our results suggest that this shift may be closely related to increasing industrialization and regulation of environmental regulation of water quality.

Industrial development in the Meiliang Bay sub-catchment, located north of Lake Taihu, was rapid in the early 1990s. Construction of massive chemical plants and direct discharge of wastewater led to rapidly increasing $\mathrm{N}$ and $\mathrm{P}$ concentrations in both the Zhihugang River and the Liangxi River. Comparative analysis of TN and TP from 1992 to 1995 indicated that the average annual TN and TP concentration were increased quickly (Fig. 6a-d). During this period, from the perspective of $\mathrm{TN}$ and $\mathrm{TP}$ changes, average annual TN:TP decreased from 34 to 23 and from 35 to 17 in the Liangxi and Zhihugang Rivers, respectively, indicating that $\mathrm{P}$ concentrations increased more quickly than those of $\mathrm{N}$ in these rivers. This change in TN:TP likely promoted the formation of $\mathrm{N}$ limitation throughout the following year.

In 1998, TSI deviations indicated that the pattern of year-round $\mathrm{N}$ limitation had begun to transition back to seasonal shifts between $\mathrm{N}$ and $\mathrm{P}$ limitation as in years prior to 1995 . This transition was attributed to generally reduced nutrient concentrations caused in part by the plan to reduce external nutrient inputs from the catchment that was imposed by the local government. Between 1996 and the end of 1998, management organizations of the Lake Taihu basin committed to reduce enterprise wastewater, a plan that was called Zero Actions (Wang et al., 2009; Paerl et al., 2011). In the upstream watershed, particularly in industrial areas in the countryside, wastewater discharge control was mandated. No untreated wastewater in the catchment was allowed to be discharged into the rivers (information sourced from an annual report of the Chinese Environmental Protection Bureau 1996). These measures led to a considerable decline in $\mathrm{P}$ and $\mathrm{N}$ loading after 1996, and the water quality response in Meiliang Bay was apparent at sampling stations E1 and E2 (Fig. 6). In both the Liangxi and Zhihugang Rivers, TN:TP increased from 23 to 27 and from 12 to 18 , respectively, indicating that $P$ concentrations were substantially reduced during 19961998. Thus, these management actions (i.e., Zero Actions plan) reduced $\mathrm{N}$ and $\mathrm{P}$ inputs into Meiliang Bay over a short time period and facilitated a return to the seasonal pattern of limitation seen prior to 1995.

\section{Seasonal nutrient limitation and regulation of eutrophication}

To identify the relationship between nutrient limitation (TSIN-TSIP) and the response of phytoplankton chlorophyll-a in different seasons, a generalised additive model (GAM) was utilized with time and nutrient limitation as explanatory variables. In total, these two explanatory variables explained $23.1 \%$ of the variation in Chl-a. We also considered the interaction between nutrient limitation and season.

The model showed the relationship between Chl-a and time had two humps corresponding to the summers of 1996 and 2008 (Fig. 7a), implying that Meiliang Bay experienced two severe blooms at these times. The deviation between TSIN and TSIP, which indicates the nature of nutrient limitation of phytoplankton, followed a right-skewed distribution in the winter-spring season (Fig. 7b) and a left-skewed distribution in summer-autumn season (Fig. 7c)

In the winter and spring, this right-skewed distribution, along with some outlier values (over 15) (Fig. 7b), reflected the frequency of significant P limitation in Meiliang Bay. Enter winter, Cyanobacteria can store P during sedimentary phases to over-winter accompany with P limitation (Ahn et al., 2002). When temperature and light become optimal for growth, cyanobacteria utilize nutrients in the water column to dominate phytoplankton communities. However, we observed that high values of Chl-a (40-50) were in accord with the normal distribution having zero as the center (Fig. 
7b). This means that phytoplankton chlorophyll-a may have accumulated without $\mathrm{P}$ limitation occurring. When phytoplankton growth entered the $\mathrm{N}$ limitation in winter-spring, cyanobacteria compete more effectively for $\mathrm{N}$ than other phytoplankton (Nõges et al., 2008). We speculated that if commonly P-limitation in winter-spring season mitigated or shifted due to TP increased in Meiliang Bay, it would give an suitable N:P stoichiometry for cyanobacteria growth (Schindler et al., 2008). Therefore, relatively high concentration of $\mathrm{N}$ and $\mathrm{P}$ nutrients, and appearance of $\mathrm{N}$ limitation in winter and spring could partly indicate the high Chl-a value in the whole year in 1996. In the summer and autumn, $\mathrm{N}$ limitation was dominant. However, peak values of Chl-a corresponded to a deviation value of -10 (Fig. 7c), which indicates only weak $\mathrm{N}$ limitation. It may be suggested that phytoplankton community is co-limited by $\mathrm{N}$ and $\mathrm{P}$ during summer and fall in Meiliang Bay, as the studying results that $\mathrm{N}$ was the primary limiting factor, with $\mathrm{P}$ being a secondarily limiting nutrient in summer and fall pointed out by Xu et al. (2010) and Paerl et al. (2011). The forming process and mechanism may be correlated with seasonal limiting state presented by nutrient cycle in major inflowing rivers (Wang et al., 2014) and nutrient lake-wide nutrient circulation in a long water residence time of approximately 1 year, such as sedimentation and regeneration of nutrient as well as algal uptake. Increases in summer DIP may be caused by elevated $\mathrm{pH}$ and anaerobic conditions, and faster turnover of $\mathrm{P}$ relative to $\mathrm{N}$ in lakes is a widely acknowledged phenomenon (Harris, 1986). Hence, more rapid recycling of $\mathrm{P}$ than $\mathrm{N}$ in Meiliang Bay likely caused maximal algal biomass during weak $\mathrm{N}$ limitation.

Utilizing TSI deviations in long-term datasets to explore the dynamics of nutrient limitation in the water column could assist the development of science-based regulation and engineering solutions for water remediation. For example, Havens (1995) utilized the TSI deviation method in Lake Okeechobee, the largest shallow lake in the USA, to determine spatial patterns of nutrient limitation across various lake zones over interannual temporal scales. It is found that secondary $\mathrm{N}$ limitation was a transition phase that remained nearly a decade. In Lake Okeechobee, $\mathrm{N}$ reduction can drive blooms of $\mathrm{N}$-fixing cyanobacteria (Mccarthy et al., 2009); therefore, to restore water quality in the lake, a plan was proposed to reduce $P$ concentrations to create the historical natural P-limited conditions in Lake Okeechobee (Mccarthy et al., 2009). In Meiliang Bay, however, the cyanobacterial community is dominated by Microcystis spp., which is not an N-fixing species (Chen et al., 2003a; Chen et al., 2003b; Mccarthy et al., 2009). Some studies in Meiliang Bay have observed that $\mathrm{N}$-fixation does not seem to occur, even by the genera Anabeana and Aphanizomenon (Mccarthy et al., 2007), which suggests that $\mathrm{N}$ fixation efficiency is limited. Hence, long-term seasonal nutrient transform pattern and potential $\mathrm{N}$ and $\mathrm{P}$ co-limitation in summer and fall suggested that to regulate cyanobacterial blooms in Lake Taihu, it is essential to reduce not only P loads, but also $\mathrm{N}$ inputs into the lake (Xu et al., 2010; Paerl et al., 2011).
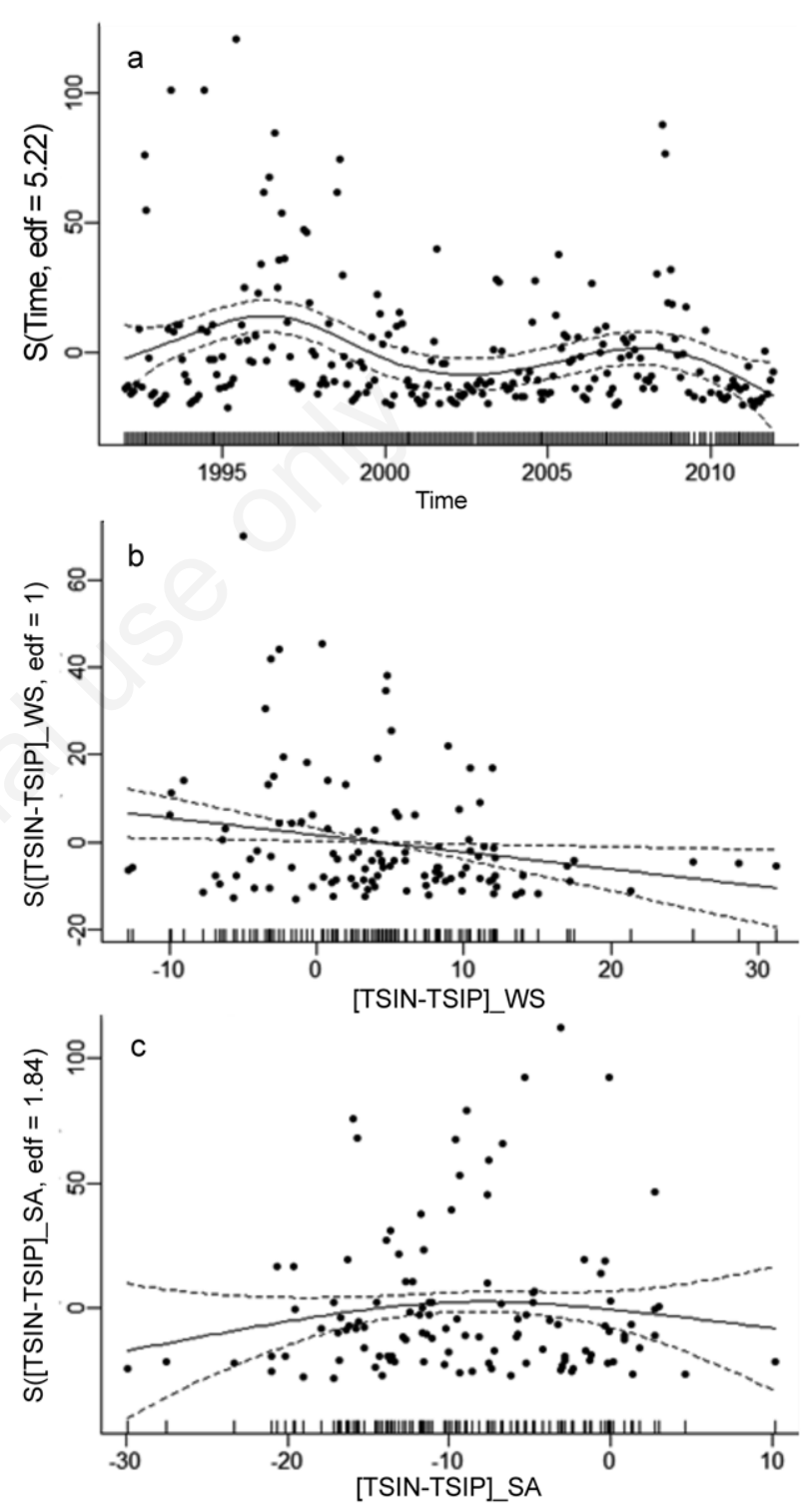

Fig. 7. Fitted model plot for Time and TSIN-TSIP by different season, corresponding to the reduced GAM for Chl-a. Each plot displays the response of Chl-a to the individual explanatory variable with dashed lines to indicate \pm 2 standard errors, and "edf" represents the estimated degrees of freedom used to fit each variable. (a) The relationship between Chla and the time series. Chl-a was affected by different seasons of TSIN-TSIP, which was divided by the (b) winter-spring effect (represented as [TSIN-TSIP]_WS) and the (c) summer-autumn effect (represented as [TSIN-TSIP]_SA). The solid lines show the GAM regressions fitted to each relationship, with dotted lines giving the confidence interval of the mean trend line. The symbols represent single samples taken during four seasons, winter-spring and summer-autumn for Chl-a, respectively. 


\section{CONCLUSIONS}

The present study evaluated long-term fluctuations in eutrophication and patterns of nutrient limitation between 1992 and 2011 in Meiliang Bay, Lake Taihu. Riverine inputs of $\mathrm{N}$ and $\mathrm{P}$ strongly affected the magnitude of nutrient concentrations and their temporal variability in Meiliang Bay. Specifically, N inputs into the bay were mainly derived from inflowing rivers, whereas influx from the sediment was also an important source of P. Analysis of TSI deviations revealed that nutrient limitation status was strongly connected to phytoplankton chlorophyll-a in all four seasons in Meiliang Bay. Thus, the results of this study indicate that government may need to simultaneously consider seasonal differences in nutrient loads and patterns of nutrient limitation when planning $\mathrm{N}$ and $\mathrm{P}$ reduction with the aim of reducing algal blooms in Meiliang Bay.

In addition, given the temporal changes and spatial heterogeneity of Lake Taihu, improved management of the entire range of lake zones will require future studies on spatial patterns of nutrient limitation in other lake zones as well as knowledge of trophic state and nutrient limitation state in Meiliang Bay over longer periods (i.e., before the 1990s).

\section{ACKNOWLEDGMENTS}

We thank the Taihu Laboratory for Lake Ecosystem Research (TLLER) for providing water quality data from 1992-2008. We thank Jinju Geng, Zhenkui Li, Mei Li and Lin Xiao for providing data from 2009-2011. We also thank Wen Xiong and Yulei Wang for assistance with the in situ monitoring. This research was supported by the National Basic Research Program (973) of China (No. 2008CB418003), Major State Water Pollution Control and Treatment Technique Program of China (No. 2013ZX07101014-05), and the Natural Science Foundation of Jiangsu Province (BK20140603).

\section{REFERENCES}

Ahn CY, Chung AS, Oh HM, 2002. Rainfall, phycocyanin, and $\mathrm{N}$ :P ratios related to cyanobacterial blooms in a Korean large reservoir. Hydrobiologia 474:117-124.

Aldridge FJ, Phlips EJ, Schelske CL, 1995. The use of nutrient enrichment bioassays to test for spatial and temporal distribution of limiting factors affecting phytoplankton dynamics in Lake Okeechobee, Florida. Arch. Hydrobiol. Beih. Ergebn. Limnol. 45:177-190.

Carlson RE, 1977. A trophic state index for lakes1. Limnol. Oceanogr. 22:361-369.

Carmichael WW, 1992. Cyanobacteria secondary metabolites the cyanotoxins. J. Appl. Bacteriol. 72:445-459.

Chen XF, Yang LY, Xiao L, Miao AJ, Xi BD, 2012. Nitrogen removal by denitrification during cyanobacterial bloom in Lake Taihu. J. Freshwat. Ecol. 27:243-258.

Chen XM, Wo F, Chen C, Fang K, 2010. Seasonal changes in the concentrations of nitrogen and phosphorus in farmland drainage and groundwater of the Taihu Lake region of China. Environ. Monit. Assess. 169:159-168.

Chen YW, Fan CX, Teubner K, Dokulil MT, 2003a. Changes of nutrients and phytoplankton chlorophyll-a in a large shallow lake, Taihu, China: an 8-year investigation. Hydrobiologia 506:273-279.

Chen YW, Qin BQ, Teubner K, Dokulil MT, 2003b. Long-term dynamics of phytoplankton assemblages: Microcystis-domination in Lake Taihu, a large shallow lake in China. J. Plankton Res. 25:445-453.

Conley DJ, 2012. Ecology: save the Baltic Sea. Nature 486: 463-464.

Conley DJ, Paerl HW, Howarth RW, Boesch DF, Seitzinger SP, Havens KE, Lancelot C, Likens GE, 2009. Controlling eutrophication: nitrogen and phosphorus. Science 323:10141015.

Dokulil MT, Chen W, Cai Q, 2000. Anthropogenic impacts to large lakes in China: the Tai Hu example. Aquat. Ecosyst. Health Manage. 3:81-94.

Dokulil MT, Teubner K, 2000. Cyanobacterial dominance in lakes. Hydrobiologia 438:1-12.

Guo L, 2007. Doing battle with the green monster of Taihu Lake. Science 317:1166.

Harris GP, 1986. Phytoplankton ecology. Chapman and Hall, London: 384 pp.

Havens KE, 1995. Secondary nitrogen limitation in a subtropical lake impacted by non-point source agricultural pollution. Environ. Pollut. 89:241-246.

Huisman J, Matthijs, Hans CP, Visser, Petra M, 2005. Harmful cyanobacteria. Springer Netherlands: $243 \mathrm{pp}$.

Jin XC, Tu Q, 1990. [The standard methods for observation and analysis in lake eutrophication].[Book in Chinese]. Chinese Environmental Science Press, Beijing: 240 pp.

Kratzer CR, Brezonik PL, 1981. A Carlson-type trophic state index for nitrogen in Florida Lakes. Water Resour. Bull. 17:713-715.

Liu YM, Chen W, Li DH, Huang ZB, Shen YW, Liu YD, 2011. Cyanobacteria-/cyanotoxin-contaminations and eutrophication status before Wuxi drinking water crisis in Lake Taihu, China. J. Environ. Sci. China 23:575-581.

Lorenzen CJ, 1967. Determination of chlorophyll and pheopigments: spectrophotometric equations. Limnol. Oceanogr. 12:343-346.

Mccarthy MJ, James RT, Chen YW, East TL, Gardner WS, 2009. Nutrient ratios and phytoplankton community structure in the large, shallow, eutrophic, subtropical Lakes Okeechobee (Florida, USA) and Taihu (China). Limnology 10:215-227.

Mccarthy MJ, Lavrentyev PJ, Yang LY, Zhang L, Chen YW, Qin BQ, Gardner WS. 2007. Nitrogen dynamics and microbial food web structure during a summer cyanobacterial bloom in a subtropical, shallow, well-mixed, eutrophic lake (Lake Taihu, China), p. 195-207. In: B. Qin, Z. Liu and K. Havens (eds.), Eutrophication of shallow lakes with special reference to Lake Taihu, China. Springer.

Mcgill R, Tukey JW, Larsen WA, 1978. Variations of box plots. Am. Stat. 32:12-16.

Nõges T, Laugaste R, Nõges P, Tõnno I. 2008. Critical N:P ratio for cyanobacteria and N2-fixing species in the large shallow temperate lakes Peipsi and Vortsjärv, North-East Europe, p. 
77-86. In: T. Nõges, R. Eckmann, K. Kangur, P. Nõges, A. Reinart, G. Roll, H. Simola and M. Viljanen (eds.), European large lakes ecosystem changes and their ecological and socioeconomic impacts. Springer.

Paerl HW, 1988. Nuisance phytoplankton blooms in coastal, estuarine, and inland waters. Limnol. Oceanogr. 33:823-847.

Paerl HW, Huisman J, 2008. Blooms like it hot. Science 320:57.

Paerl HW, Xu H, Mccarthy MJ, Zhu GW, Qin BQ, Li YP, Gardner WS, 2011. Controlling harmful cyanobacterial blooms in a hyper-eutrophic lake (Lake Taihu, China): The need for a dual nutrient (N \& P) management strategy. Water Res. 45:1973-1983.

Qiao J, Yang LZ, Yan TM, Xue F, Zhao D, 2012. Nitrogen fertilizer reduction in rice production for two consecutive years in the Taihu Lake area. Agric. Ecosyst. Environ. 146:103-112.

Qin BQ, Gao G, Zhu GW, Zhang YL, Song YZ, Tang XM, Xu H, Deng JM, 2013. Lake eutrophication and its ecosystem response. Chin. Sci. Bull. 58:961-970.

Qin BQ, Hu WP, Chen WM, 2004. [Process and mechanism of environmental changes of the Taihu Lake].[Book in Chinese]. Science Press, Beijing.

Qin BQ, Xu PZ, Wu QL, Luo LC, Zhang YL, 2007. Environmental issues of lake Taihu, China. Hydrobiologia 581:3-14.

Qin BQ, Zhu GW, Gao G, Zhang YL, Li W, Paerl HW, Carmichael WW, 2010. A drinking water crisis in Lake Taihu, China: linkage to climatic variability and lake management. Environ. Manage. 45:105-112.

Redfield AC, 1958. The biological control of chemical factors in the environment. Am. Sci.:230A-221.

Søndergaard M, Jensen JP, Jeppesen E, 2003. Role of sediment and internal loading of phosphorus in shallow lakes. Hydrobiologia 506:135-145.

Salmaso N, Buzzi F, Garibaldi L, Morabito G, Simona M, 2012. Effects of nutrient availability and temperature on phytoplankton development: a case study from large lakes south of the Alps. Aquat. Sci. 74:555-570.

Schindler DW, Hecky R, Findlay D, Stainton M, Parker B, Paterson M, Beaty K, Lyng M, Kasian S, 2008. Eutrophication of lakes cannot be controlled by reducing nitrogen input: results of a 37-year whole-ecosystem experiment. P. Natl. Acad. Sci. USA 105:11254-11258.

Song LR, Chen W, Peng L, Wan N, Gan NQ, Zhang XM, 2007. Distribution and bioaccumulation of microcystins in water columns: a systematic investigation into the environmental fate and the risks associated with microcystins in Meiliang Bay, Lake Taihu. Water Res. 41:2853-2864.

Tao M, Xie P, Chen J, Qin BQ, Zhang DW, Niu Y, Zhang M,
Wang Q, Wu LY, 2012. Use of a generalized additive model to investigate key abiotic factors affecting microcystin cellular quotas in heavy bloom areas of Lake Taihu. PloS ONE 7:e32020.

Vant WN, Hua YZ, Jiang YC, McBride GB, Roper DS, Wang Q, 1998. Analysis of Lake Taihu eutrophication data 19891993. J. Lake Sci. 10(Suppl):143-154.

Wang L, Cai YL, Fang LY, 2009. Pollution in Taihu Lake China: causal chain and policy options analyses. Front Earth Sci. Chin. 3:437-444.

Wang P, Ren L, Wang C, Qian J, Hou J, 2014. Presence and patterns of alkaline phosphatase activity and phosphorus cycling in natural riparian zones under changing nutrient conditions. J. Limnol. DOI: 0.4081/jlimnol.2014.1004

Wood S, 2006. Generalized additive models: an introduction with R. CRC Press: 410 pp.

Wood SN, 2011. Fast stable restricted maximum likelihood and marginal likelihood estimation of semiparametric generalized linear models. J. Roy. Stat. Soc. B 73:3-36.

Xie LQ, Xie P, Li SX, Tang HJ, Liu H, 2003. The low TN:TP ratio, a cause or a result of microcystis blooms? Water Res. 37:2073-2080.

Xu H, Paerl HW, Qin BQ, Zhu GW, Gao G, 2010. Nitrogen and phosphorus inputs control phytoplankton growth in eutrophic Lake Taihu, China. Limnol. Oceanogr. 55:420-432.

Xu S, Huang B, Wei ZB, Luo J, Miao AJ, Yang LY, 2013. Seasonal variation of phytoplankton nutrient limitation in Lake Taihu, China: a monthly study from year 2011 to 2012 . Ecotoxicol. Environ. Saf. 94:190-196.

Yang M, Yu JW, Li ZL, Guo ZH, Burch M, Lin TF. 2008. Taihu Lake not to blame for Wuxi's woes. Science 319:158.

Yue DM, Peng YK, Qian X, Xiao L, 2014. Spatial and seasonal patterns of size-fractionated phytoplankton growth in Lake Taihu. J. Plankton Res. 36:709-721.

Zhang XJ, Chen C, Ding JQ, Hou AX, Li Y, Niu ZB, Su XY, Xu YJ, Laws EA, 2010. The 2007 water crisis in Wuxi, China: analysis of the origin. J. Hazard. Mater. 182:130-135.

Zhu GW, 2008. Eutrophic status and causing factors for a large, shallow and subtropical Lake Taihu, China. J. Lake Sci. 1:005.

Zhu M, 1994. Preliminary study on water quality protection in Lake Taihu, p. 269-279. In: H. Sund, X. Yu, H. Stabel, K. Yuan, W. Geller and F. She (eds.), Environmental protection and lake ecosystem. China Science and Technology Press, Beijing.

Zuur A, Ieno EN, Walker N, Saveliev AA, Smith GM. 2009. Mixed effects models and extensions in ecology with R. Springer, New York: 574 pp. 